A paper by M. Menes and L. H. Fisher (New York University) gave an account of how they have measured the formative time-lag of a discharge on positive metal points $(0.07-0.3 \mathrm{~mm}$. radius) in dry air irradiated with ultra-violet light, the negative electrode being a plane at a distance up to $1.5 \mathrm{~cm}$. They found that when the pressure was increased from 30 to $700 \mathrm{~mm}$. of mercury, the time-lag at threshuld potential decreased from 1 to about $0.1 \mu$ sec., depending only slightly on the radius, distance and illumination. This and the small lag indicate that the multiplication processes leading to the starting of a corona discharge are controlled by the gas.

The starting of a discharge between plane metal electrodes 1-4 cm. apart at pressures of less than or equal to $1 \mu$ mercury and frequencies of 30-90 Mc./s. has been investigated by $A$. $J$. Hatch and $H$. B. Williams (New Mexico College), and they have observed that the starting field decreases with decreasing frequency as known for electrodeless discharges - until the cut-off frequency is reached. An avalanche of secondary electrons supplied by the electrodes is thought to initiate the discharge. However, when a strong field is quickly applied and then slowly lowered, a second field/frequency curve is obtained which lies above the first; this branch seems to depend on surface conditions and gas content of the electrodes.

A. von Engel (University of Oxford) dealt with the growth of an electrodeless discharge in high-frequency electric fields at very low pressure, based on work by G. Francis. From oscillegrams of the discharge current and from theory, it is concluded that initially an avalanche of secondary electrons from the glass wall is formed, rising exponentially with time; then positive ions are prcduced in the gas, reducing the speed of impact of electrons on the walls and thus secondary emission. Finally, the ion concentration becomes so large that the amplitude of electron oscillation is reduced. The losses to the wall are ascribed to self-repulsion.

A. VON ENGEL

\section{COLOUR VARIATION IN THE BRUSH-TONGUED LORIES}

$\mathrm{A}^{\mathrm{T}}$

T a meeting of the British Ornithologists' Union held in the Zoological Society's lecture room on November 22, Dr. A. J. Cain, lecturer in zoology in the University of Oxford, gave a lecture on colour variation in the brush-tongued lories of the genus Trichoglossus inhabiting Australia and the islands of the South West Pacific, where the commoner forms are known as the blue mountain lory and the coconut lory. With specimens kindly loaned from the Reference Collections in the British Museum and by means of attractive Kodachrome slides, Dr. Cain showed that most of the random variation and distribution described by some authors for these birds could be explained satisfactorily in the light of modern evolutionary ideas.

Brightly coloured brush-tongued lories with striking orange and blue or scarlet and black under. sides in almost endless. variation live in flocks in open wooded areas, on islands from Bali to New Guinea with the Solomon Islands, and from Eastern Australia to the Caroline Islands. Much of the variation is correlated with local climate; but Trichoglossus hoematodus weberi from Flores is a subspecies which is green all over, lacking the red and black underparts of Trichoglossus hoematodus mitchelli from Bali and Lombok or the green and yellow underparts of Trichoglossus hoematodus capistratus from Timor.

In Flores this subspecies of Trichoglossus lives quietly in the woods, clad in the sombre jungle green uniform of the forest dweller which seeks its food far and wide in the presence of its enemies. It has apparently changed its ecological niche.

In contrast, there lives on Ponape Island in the Carolines 1 richoglossus homatodus rubiginosus, separated by nearly a thousand miles from its nearest relatives in the Solomon Islands. Except for its tail, it is a uniform, dull blood-red colour, with soft, silky plumage unlike the hard features of all the other forms. This subspecies meets no visual predators in its island and needs no recognition marks between friends, for there are no other lories or parakeets with whom confusion can occur. Consequently it has abandoned the usual coloration in the forms, which is cryptic dorsally, and variegated ventrally.

\section{VACUUM PHYSICS}

GUNDAMENTALLY, the study of high vacuum is a branch of physics. However, following war demands, there has been a rapid development in recent years of large-scale and industrial applications of vacuum processes, and a new branch of engineering, in which high-vacuum technique dominates, has been developed. This new development, together with the considerable improvements in vacuum technique and equipment which have accompanied it, is not as widely known to research workers in the various branches of science as it deserves. The Midland Branch of the Institute of Physics is therefore to be congratulated on having taken the initiative in arranging an exhibition of modern vacuum equipment and a symposium on vacuum physics during June 27-28, 1950. The proceedings of the meeting have now been published by the Institute of Physics in a special supplement of the Journal of Scientific Instruments*.

The exhibition and symposium were held in the University of Birmingham, at the invitation of Prof. M. L. Oliphant, and some two hundred members of university, government research and industrial laboratories attended. A wide range of pumps, gauges and associated equipment was exhibited by the leading manufacturers of vacuum equipment in Great Britain. The exhibits were attractively laid out and included many working models arranged for actual demonstration. The Physics Department of the University of Birmingham put on show some pieces of vacuum equipment of a specialized nature which had been developed to meet the requirements of the nuclear research programme carried out in that Department, and several conference members were given the opportunity of inspecting the large particle accelerators under construction in the Department. Altogether, eleven papers, each of which was followed by a lively discussion, were read.

The proceedings of the symposium may be divided into three sections which deal with the production and measurement of high vacua, leak detection and modern applications of high-vacuum processes respectively. In the first section, D. R. Goddard discusses in rather a general manner the *J. Sci. Instr., Supp. 1 (London: Institute of Physics, 1051 ; 158.). 